\title{
Caracterização de concretos com baixo consumo de cimento Portland
}

\author{
T.G. Cândido ${ }^{1 *}$, G. R Meira², M. Quattrone ${ }^{3}$, D. E. Angulo ${ }^{3}$, V. M. John \\ *Autor de Contato: taissa.guedes@cemtec.org \\ ${ }^{1}$ National Institute on Advanced Eco-Efficient Cement-Based Technologies, Universidade Federal da Paraíba, João \\ Pessoa, Paraíba, Brasil. \\ ${ }^{2}$ National Institute on Advanced Eco-Efficient Cement-Based Technologies - Instituto Federal da Paraíba, João \\ Pessoa, Paraíba, Brasil \\ ${ }^{3}$ National Institute on Advanced Eco-Efficient Cement-Based Technologies - Universidade de São Paulo, São Paulo, \\ Brasil
}

\section{RESUMO}

O setor da construção civil vem buscando alternativas para minimizar os seus impactos ambientais. Dentro deste contexto, busca-se a redução do consumo de cimento Portland no concreto. Isto se deve ao fato da indústria do cimento ser responsável por mais de 5\% das emissões antropogênicas de $\mathrm{CO}_{2}$. Este trabalho avaliou a resistência à compressão, a absorção de água e a velocidade de propagação de ondas ultrassônicas em concretos com consumos de cimento de $150 \mathrm{~kg} / \mathrm{m}^{3}(\mathrm{C} 150)$, $250 \mathrm{~kg} / \mathrm{m}^{3}(\mathrm{C} 250)$ e $350 \mathrm{~kg} / \mathrm{m}^{3}$ (C350), este último usado como concreto de referência. Os resultados demonstraram que o concreto C250 apresentou o melhor desempenho mecânico, e ambos os concretos com menores teores de cimento obtiveram maior eficiência quanto ao uso de ligante em relação ao concreto de referência. Esses concretos também obtiveram menor teor de vazios e absorção de água, indicando sua menor porosidade.

Palavras-chave: Concreto sustentável; baixo teor de ligante; filer calcário; desempenho mecânico; durabilidade.

\section{RESUMEN}


El sector de la construcción civil ha buscado alternativas para minimizar sus impactos ambientales. En ese contexto, hay una búsqueda en reducir el consumo de cemento Portland en el hormigón. Esto se debe al hecho de que la industria del cemento es responsable por más del $5 \%$ de las emisiones antropogénicas de $\mathrm{CO}_{2}$. Este trabajo evaluó la resistencia a compresión, la absorción de agua y velocidad de propagación de ondas ultrasónicas en hormigones con contenidos de cemento de $150 \mathrm{~kg} / \mathrm{m}^{3}, 250 \mathrm{~kg} / \mathrm{m}^{3}$ y $350 \mathrm{~kg} / \mathrm{m}^{3}$. Este último fue usado como hormigón de referencia. Los resultados mostraron que el hormigón C250 presentó el mejor desempeño mecánico y ambos los hormigones con menor contenido de cemento presentaron mayor eficiencia en el uso de del aglomerante en relación al hormigón de referencia. Estos hormigones también presentaron menor cantidad de vacíos y absorción de agua, lo que indica su menor porosidad.

Palabras clave: Concreto sostenible; bajo contenido de cementante; filer; desempeño mecánico; durabilidad.

\begin{abstract}
The civil construction sector has been looking for alternatives to minimize its environmental impacts. Within this context, there is an aim to reduce the Portland cement consumption in concrete. This is due to the fact that the cement industry is responsible for more than $5 \%$ of the anthropogenic $\mathrm{CO}_{2}$ emissions. This work evaluated the compressive strength, water absorption, and ultrasonic pulse velocity in concretes with cement contents of $150 \mathrm{~kg} / \mathrm{m}^{3}$ (C150), $250 \mathrm{~kg} / \mathrm{m}^{3}$ (C250), and $350 \mathrm{~kg} / \mathrm{m}^{3}$ (C350), this last one was used as reference concrete. The results showed that the $\mathrm{C} 250$ concrete presented the best mechanical performance, and both concretes with lower cement contents obtained greater efficiency regarding the use of binder in relation to the reference concrete. These concretes also had lower void content and water absorption, indicating their lower porosity.
\end{abstract}

Key words: Sustainable concrete; low binder content; limestone filer; mechanical performance; durability.

\title{
1. INTRODUÇÃO
}

A indústria da construção civil gera impactos ambientais em toda a sua cadeia produtiva. Ela é responsável por consumir mais da metade dos recursos naturais extraídos do planeta na produção e manutenção do ambiente construído. Após a extração, o processo industrial das matérias-primas utiliza energia e emitindo gases que contribuem ao efeito estufa. Além disso, ainda ocorrem perdas de materiais nas fases de transporte, comercialização e construção, gerando grandes volumes de resíduos sólidos (CBCS, 2014).

O concreto é o material de construção mais utilizado, e seu maior impacto ambiental vem da produção do cimento Portland, que gera aproximadamente 5\% das emissões antropogênicas de $\mathrm{CO}_{2}$ do mundo. Espera-se que essa parcela aumente, uma vez que a demanda por produtos à base de cimento deve se multiplicar por um fator de 2,5 nos próximos 40 anos e as estratégias tradicionais de mitigação de emissões, focadas na produção de cimento, não serão capazes de compensar esse crescimento (Damineli et al., 2010; IPCC 2021). O aumento da demanda por materiais de construção exige uma maneira alternativa de desenvolver ou derivar materiais de construção de diferentes fontes (Smol et al., 2015).

Nesse contexto, a redução do teor de clínquer no cimento e de cimento no concreto surge como uma estratégia pra mitigar suas emissões de $\mathrm{CO}_{2}$. Esta redução tem efeitos positivos na avaliação 
do ciclo de vida ambiental do concreto e pode ser alcançada pela otimização da mistura (Proske $e t$ al., 2014). Porém, para manter suas características de sustentabilidade, o concreto com baixo teor de cimento deve ter suas propriedades mecânicas e de durabilidade semelhantes ou superior ao concreto convencional (Müller et al., 2014).

A redução do teor do cimento Portland pode ser obtida substituindo parte desse cimento por finos como calcário, cinza volante ou escória. No entanto, deve-se priorizar o filer calcário devido a sua maior disponibilidade (Proske et al., 2014).

O consumo de cimento é tradicionalmente expresso em massa de cimento por volume de concreto $\left(\mathrm{kg} / \mathrm{m}^{3}\right)$. Porém, esta forma não tem relação com as características do concreto resultante (Rebmann e Liborio, 2013). Para melhor relacionar esse consumo de cimento com o desempenho do concreto, Damineli et al. (2010) propôs um indicador de Intensidade Ligante (IL) que relaciona o consumo total de ligante do concreto, em $\mathrm{kg} / \mathrm{m}^{3}$, com a resistência à compressão aos 28 dias, em MPa. Desta forma, ele indica o consumo de ligante necessário para produzir uma unidade de resistência. Damineli et al. (2010) realizaram um levantamento na bibliografia nacional e internacional e avaliaram que o IL mínimo observado foi de aproximadamente $5 \mathrm{~kg} . \mathrm{m}^{-3} / \mathrm{MPa}$, em concretos com resistência acima de $50 \mathrm{MPa}$. Para concretos com resistência abaixo de $50 \mathrm{MPa}$ o IL mais comum foi em torno de $10 \mathrm{~kg} \cdot \mathrm{m}^{-3} / \mathrm{MPa}$. Apenas aproximadamente 2,2\% dos concretos catalogados foram produzidos utilizando-se menos do que $250 \mathrm{~kg} / \mathrm{m}^{3}$ de ligantes totais. Isso é provavelmente devido aos teores mínimos de cimento estabelecido nas normas técnicas.

A redução do consumo de cimento não visa apenas garantir maior longevidade para as jazidas de matérias primas do cimento ou redução dos impactos ambientais com a exploração destas jazidas e da emissão do $\mathrm{CO}_{2}$. Um uso reduzido de cimento é também vantajoso sob alguns pontos de vista técnicos, como a retração e fluência do concreto (Rebmann, 2011).

Diante deste cenário, o objetivo deste artigo é apresentar a caracterização mecânica e das propriedades de absorção de concretos com baixo teor de cimento e elevado teor de filer calcário.

\section{PROCEDIMENTO}

\subsection{Materiais}

Os materiais utilizados nestes concretos foram agregados naturais, cimento $\mathrm{CP}-\mathrm{V}$ ARI e dois tipos de filer calcário. As propriedades físicas dos finos estão apresentadas na Tabela 1. O tipo de cimento utilizado geralmente contém uma porcentagem de adições minerais (filer calcário). A quantidade de adição foi determinada por análise termogravimétrica (TG) do pó anidro. As curvas de Termogravimetria (TG) e Curva Diferencial de $1^{\mathrm{a}}$ ordem (DTG) dos finos estão ilustradas nas Figuras 1-3 e as curvas granulométricas na Figura 4.

Tabela 1. Caracterização dos finos

\begin{tabular}{|c|c|c|}
\hline Material & $\begin{array}{c}\text { Massa específica } \\
\left(\mathbf{g} / \mathbf{c m}^{\mathbf{3}}\right)\end{array}$ & $\begin{array}{c}\text { Área superficial - } \\
\text { BET } \mathbf{N}_{\mathbf{2}} \mathbf{S S A ~} \mathbf{( m}^{\mathbf{2}} \mathbf{g} \mathbf{)}\end{array}$ \\
\hline Cimento CP-V & 3,06 & 0,9655 \\
\hline Filer calcário - PF1 & 2,76 & 3,73 \\
\hline Filer calcário - PC5 & 2,74 & 1,16 \\
\hline
\end{tabular}




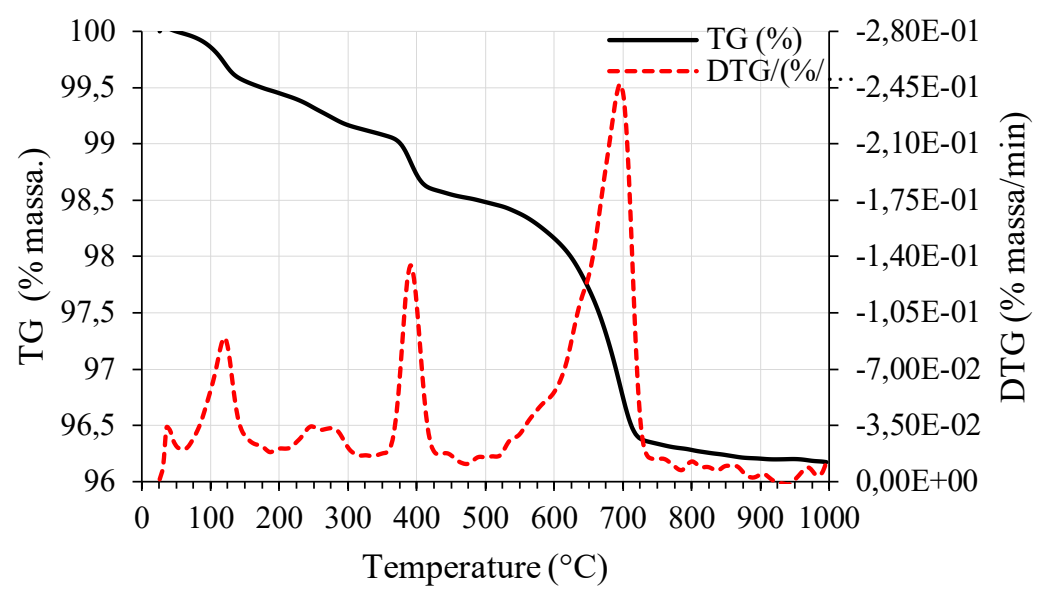

Figura 1. Termogravimetria (TG) e Curva Diferencial de $1^{\mathrm{a}}$ ordem (DTG) do cimento anidro.

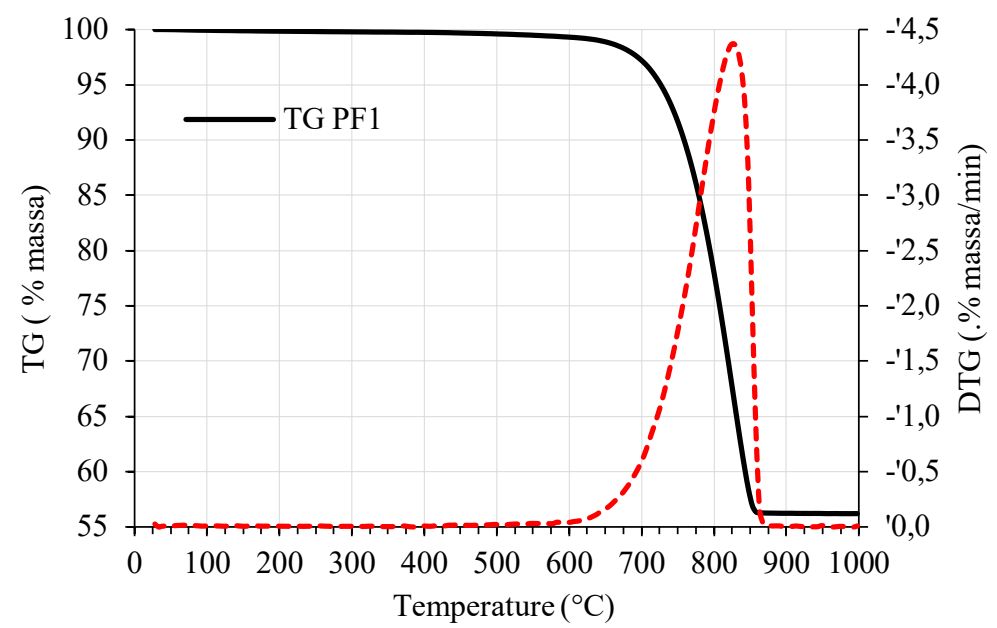

Figura 2. Termogravimetria (TG) e Curva Diferencial de $1^{\mathrm{a}}$ ordem (DTG) do filer calcário PF1.

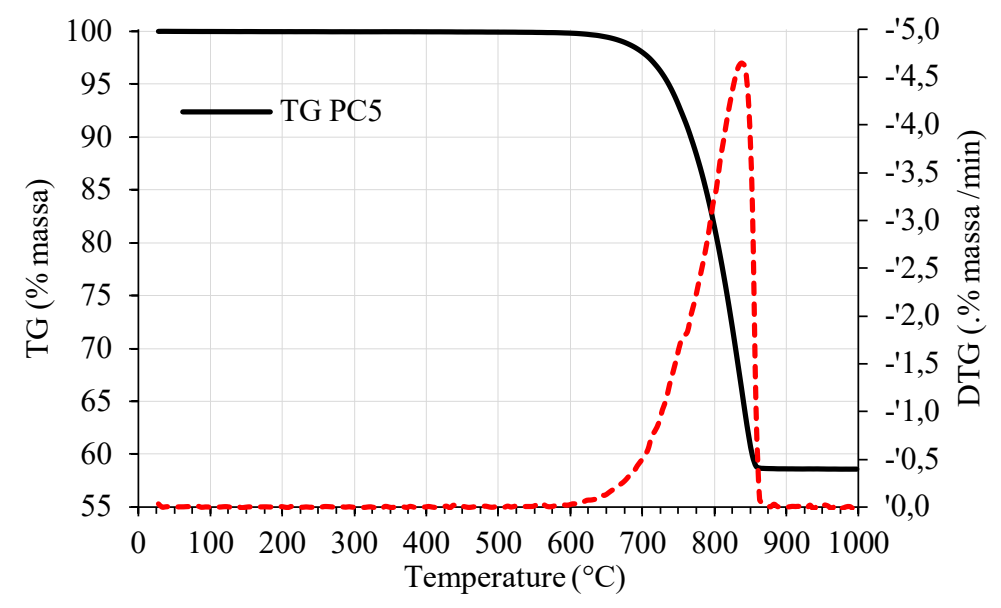

Figura 3. Termogravimetria (TG) e Curva Diferencial de $1^{\mathrm{a}}$ ordem (DTG) do filer calcário PC5. 
$\mathrm{O}$ resultado de $\mathrm{TG}$ do cimento mostra uma mudança de massa em torno de 2,2\% (faixa de temperatura 540-900 ${ }^{\circ} \mathrm{C}$ ) correspondendo a uma quantidade de $\mathrm{CaCO}_{3}$ próxima de $5 \%$. Este resultado significa que o ligante é igual a $95 \%$ em peso do cimento anidro. Já o resultado de TG dos filers indicam que ambos podem ser considerados $\mathrm{CaCO}_{3}$ puro; 98,72\% para PF1 e 94,03\% para PC5, respectivamente.

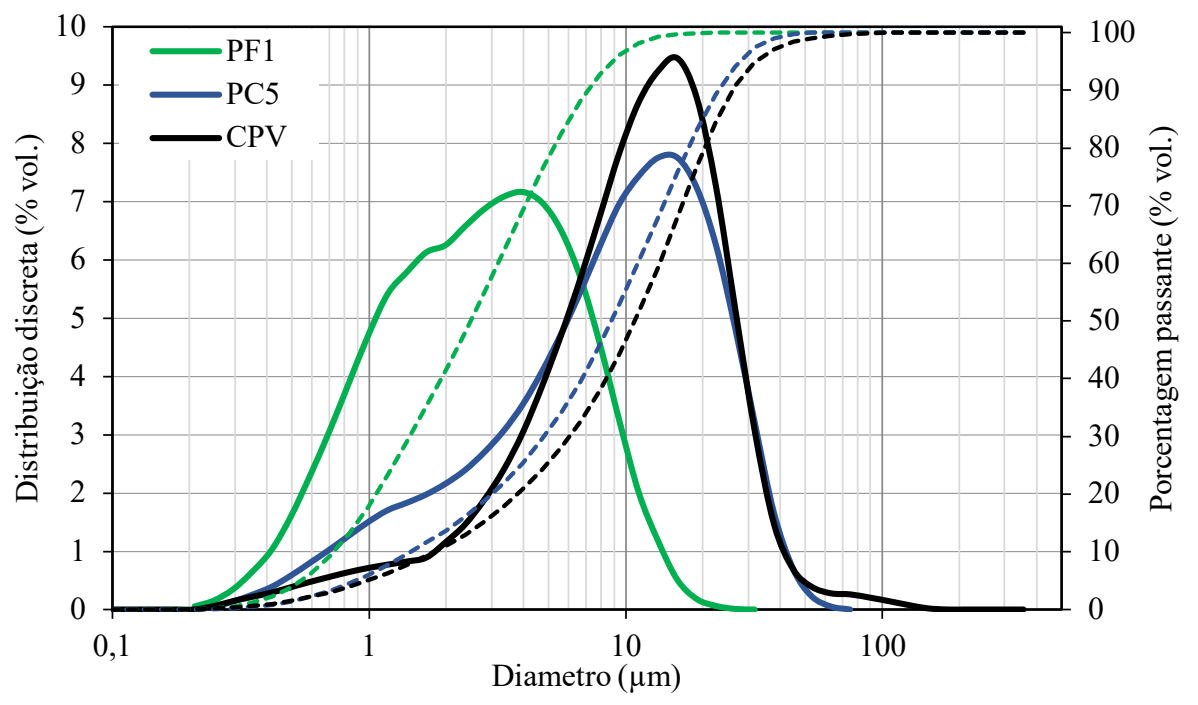

Figura 4. Distribuição granulométrica do cimento e dos filers; as linhas tracejadas indicam a porcentagem passante na peneira.

Pode-se perceber que foi utilizado um filer com curva granulométrica semelhante à do cimento, e um outro filer com partículas mais finas, e consequentemente, maior área superficial. Dessa forma, o cimento será parcialmente substituído por um filer com partículas de tamanho semelhante ao seu, e um outro filer mais fino que irá promover o empacotamento desses finos, reduzindo o teor de vazios.

Como agregados foram utilizados três areias e um cascalho. A caracterização destes materiais está apresentada na Tabela 2. A Figura 5 ilustra as curvas granulométricas destes materiais obtidas por análise de imagem dinâmica.

Tabela 2. Caracterização dos agregados

\begin{tabular}{|c|c|c|c|}
\hline Material & $\begin{array}{l}\text { Massa específica } \\
\left(\mathrm{g} / \mathrm{cm}^{3}\right)\end{array}$ & $\begin{array}{c}\text { VSA* } \\
\left(\mathrm{m}^{2} / \mathrm{cm}^{3}\right)\end{array}$ & $\begin{array}{l}\text { Dimensão máxima } \\
\text { característica }(\mathrm{mm})\end{array}$ \\
\hline Areia 1 & 2,63 & 0,5528 & 1,18 \\
\hline Areia 2 & 2,82 & 0,5826 & 1,18 \\
\hline Areia 3 & 2,74 & 0,0690 & 4,75 \\
\hline Pedrisco & 2,74 & 0,0010 & 9,50 \\
\hline
\end{tabular}

*calculado a partir da granulometria, assumindo partículas esféricas 


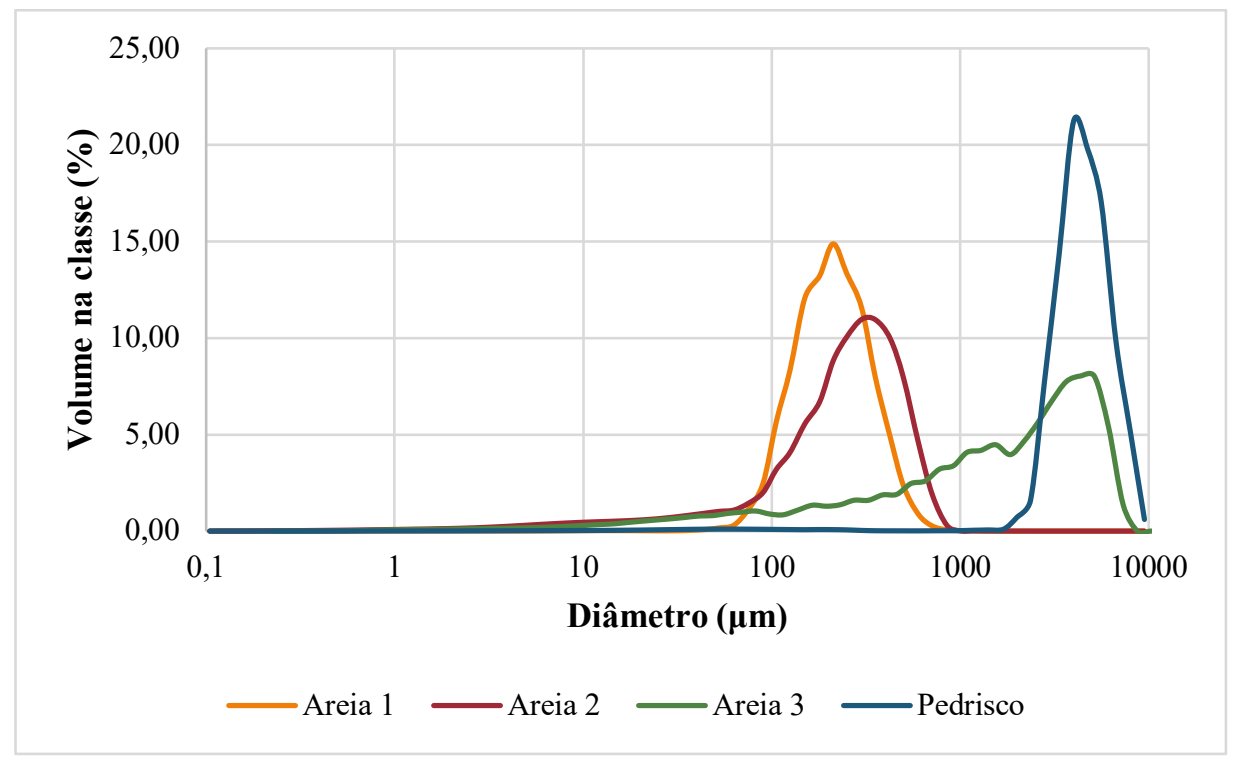

Figura 5. Curvas Granulométricas dos agregados

\subsection{Produção dos concretos}

Esta pesquisa se delimitou a trabalhar apenas com o cimento $\mathrm{CP} V$ - ARI sem adições. Foram confeccionados dois concretos com baixo consumo de cimento $\left(\mathrm{C}=250 \mathrm{~kg} / \mathrm{m}^{3}\right.$ e $\left.\mathrm{C}=150 \mathrm{~kg} / \mathrm{m}^{3}\right)$ e um concreto de referência $\left(\mathrm{C}=350 \mathrm{~kg} / \mathrm{m}^{3}\right)$. Tendo-se um total de três traços a serem avaliados, conforme apresenta a Tabela 3.

Tabela 3. Traços dos concretos avaliados

\begin{tabular}{|c|c|c|c|}
\hline Material & C150 & C250 & C350 \\
\hline Cimento CP V - ARI $\left(\mathrm{kg} / \mathrm{m}^{3}\right)$ & 150,60 & 250,00 & 350,00 \\
\hline Filer calcário PF1 $\left(\mathrm{kg} / \mathrm{m}^{3}\right)$ & 139,85 & 147,01 & 0,00 \\
\hline Filer calcário PC5 $\left(\mathrm{kg} / \mathrm{m}^{3}\right)$ & 189,25 & 93,13 & 0,00 \\
\hline Areia 1 $\left(\mathrm{kg} / \mathrm{m}^{3}\right)$ & 248,21 & 248,21 & 260,30 \\
\hline Areia 2 $\left(\mathrm{kg} / \mathrm{m}^{3}\right)$ & 228,51 & 228,51 & 239,55 \\
\hline Areia 3 $\left(\mathrm{kg} / \mathrm{m}^{3}\right)$ & 776,12 & 776,42 & 814,03 \\
\hline Pedrisco $\left(\mathrm{kg} / \mathrm{m}^{3}\right)$ & 611,94 & 611,94 & 641,49 \\
\hline Água $\left(\mathrm{kg} / \mathrm{m}^{3}\right)$ & 164,13 & 179,03 & 188,85 \\
\hline $\begin{array}{c}\text { Dispersante à base de } \\
\text { policarboxilato }(\%)\end{array}$ & $0,298 \%$ & $0,253 \%$ & $0,214 \%$ \\
\hline Relação água/cimento & 1,09 & 0,72 & 0,54 \\
\hline Relação água/finos & 0,34 & 0,37 & 0,54 \\
\hline
\end{tabular}

Na produção dos concretos testes, foi verificado a necessidade de uma adaptação na sequência de mistura para que ocorra a melhor dispersão dos materiais usados, que é fundamental para aumentar o desempenho reológico das misturas cimentícias. Por isso, o procedimento de mistura desses concretos é diferente dos concretos convencionais, e foi realizado da seguinte forma: 
I. Umedecimento das paredes da betoneira;

II. Colocação dos finos com o dispersante em pó e adição aos poucos da água, promovendo a sua mistura;

III. Colocação de toda brita, promovendo a mistura com a pasta;

IV. Colocação aos poucos da areia junto com o restante da água;

V. Verificação da necessidade de adicionar mais aditivo e/ou água.

Em todo processo, verificou-se se a mistura estava ocorrendo de forma homogênea. No concreto fresco, a consistência foi medida pelo ensaio de abatimento de tronco de cone, segundo as recomendações da NM 67 (ABNT, 2020). Também foi realizado o ensaio de massa específica pelo método indicado na NBR 9833 (ABNT, 2008). Foram moldados corpos de prova de $10 \mathrm{~cm}$ x 20 $\mathrm{cm}$. O concreto foi adensado utilizando uma mesa vibratória. Após 24 horas, os corpos de prova foram desmoldados e, em seguida, colocados em cura em câmara úmida até a idade dos ensaios.

\subsection{Caracterização do concreto}

Apesar da resistência a compressão ser a propriedade mais importante no estudo do concreto, outros parâmetros também devem ser verificados quando se trata de sua durabilidade. Portanto, neste estudo, além dos ensaios de resistência à compressão, foram realizados ensaios de ultrassom, resistividade e absorção por imersão e por capilaridade.

\subsubsection{Resistência à compressão}

O ensaio de resistência à compressão seguiu as recomendações da NBR 5739 (NBR, 2007). Os ensaios foram realizados na idade de 28 dias, A Figura 6 ilustra a execução do ensaio.

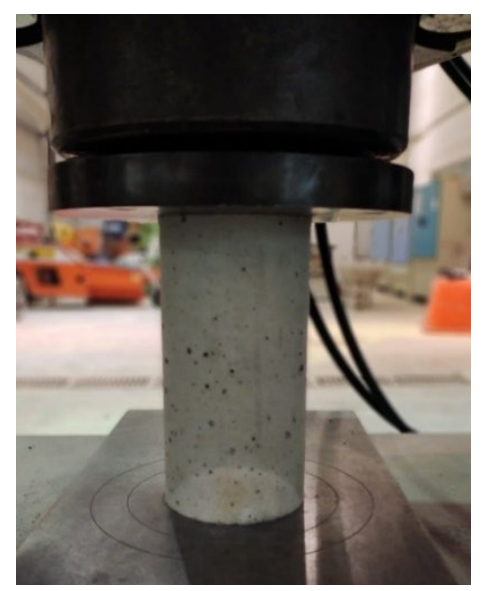

Figura 6. Execução do ensaio de resistência à compressão

\subsubsection{Ensaio de absorção por imersão e por capilaridade}

Os ensaios de absorção foram realizados na idade de 28 dias. Foram avaliados três corpos de prova cilíndricos de $10 \mathrm{~cm}$ x $5 \mathrm{~cm}$ em cada ensaio, que foram extraídos de CPs de $10 \mathrm{~cm}$ x $20 \mathrm{~cm}$. O ensaio de absorção de água por imersão foi executado segundo as recomendações da ASTM C64613, e o ensaio de absorção de água por capilaridade seguiu as recomendações da ASTM C158513. 
Na realização do ensaio de absorção de água por imersão, os corpos de prova foram colocados na estufa com temperatura de $(105 \pm 5)^{\circ} \mathrm{C}$ por um período de $72 \mathrm{~h}$. Após esse período, foram pesados e em seguida, colocados submersos em água a temperatura de $(23 \pm 2)^{\circ} \mathrm{C}$ por mais $72 \mathrm{~h}$. Completada a saturação, os corpos de prova foram então postos em um recipiente cheio de água que foi levada à ebulição, permanecendo neste estado por $5 \mathrm{~h}$. A seguir, deixou-se a água esfriar até a temperatura ambiente, quando a massa da amostra foi determinada com auxílio da balança hidrostática. Também se determinou a massa da amostra após enxugar sua superfície com um pano úmido. A partir dos resultados obtidos neste ensaio, foi possível determinar o índice de vazios, a absorção e a massa específica da amostra.

No ensaio de absorção de água por capilaridade, os corpos de prova foram secos em estufa a $(105 \pm 5)^{\circ} \mathrm{C}$ por um período de $72 \mathrm{~h}$. Em seguida, as amostras foram resfriadas até a temperatura ambiente, depois as superfícies laterais dessas amostras foram seladas e a superfície superior foi vedada com material plástico. Depois foram colocados sobre suportes, em um recipiente com nível da água até altura de $3 \mathrm{~mm}$ do fundo do corpo de prova (Figura 7). Os corpos de prova foram então retirados da água e enxugados com pano úmido para determinação da sua massa nos tempos de determinados pela norma.

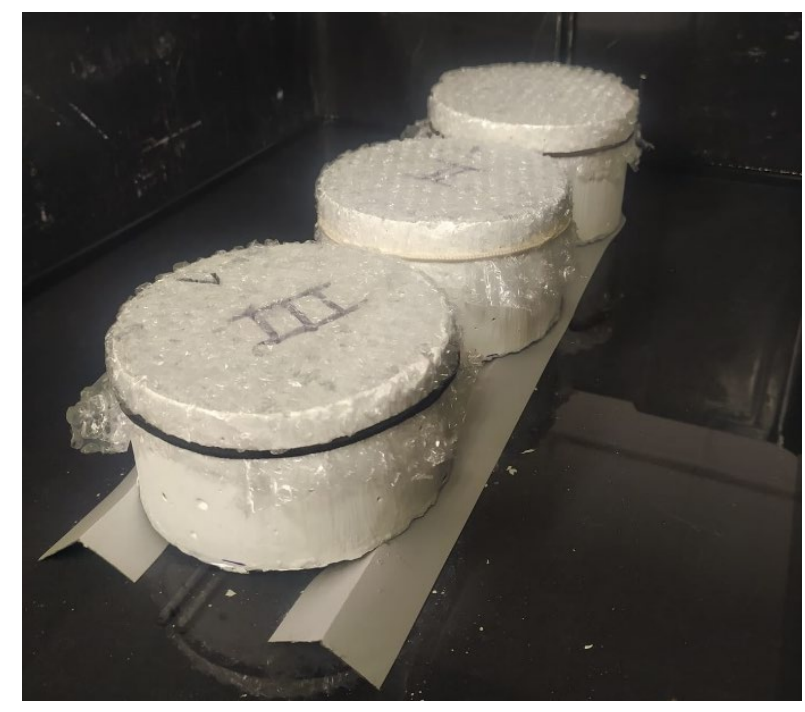

Figura 7. Condição das amostras no ensaio de absorção por capilaridade.

\subsubsection{Velocidade de propagação de onda ultrassônica}

O ensaio de ultrassom foi realizado segundo o procedimento do método de ensaio da ASTM C 597-16. A partir dos resultados desse ensaio, determinou-se o módulo de elasticidade dinâmico do concreto aos 28 dias. Para a sua realização, foi utilizado o equipamento Pundit Lab. O arranjo de transmissão foi de forma direta, pois desta maneira as ondas são recebidas com mais intensidade. Portanto, os transdutores foram colocados em faces opostas, conforme ilustra a Figura 8. 


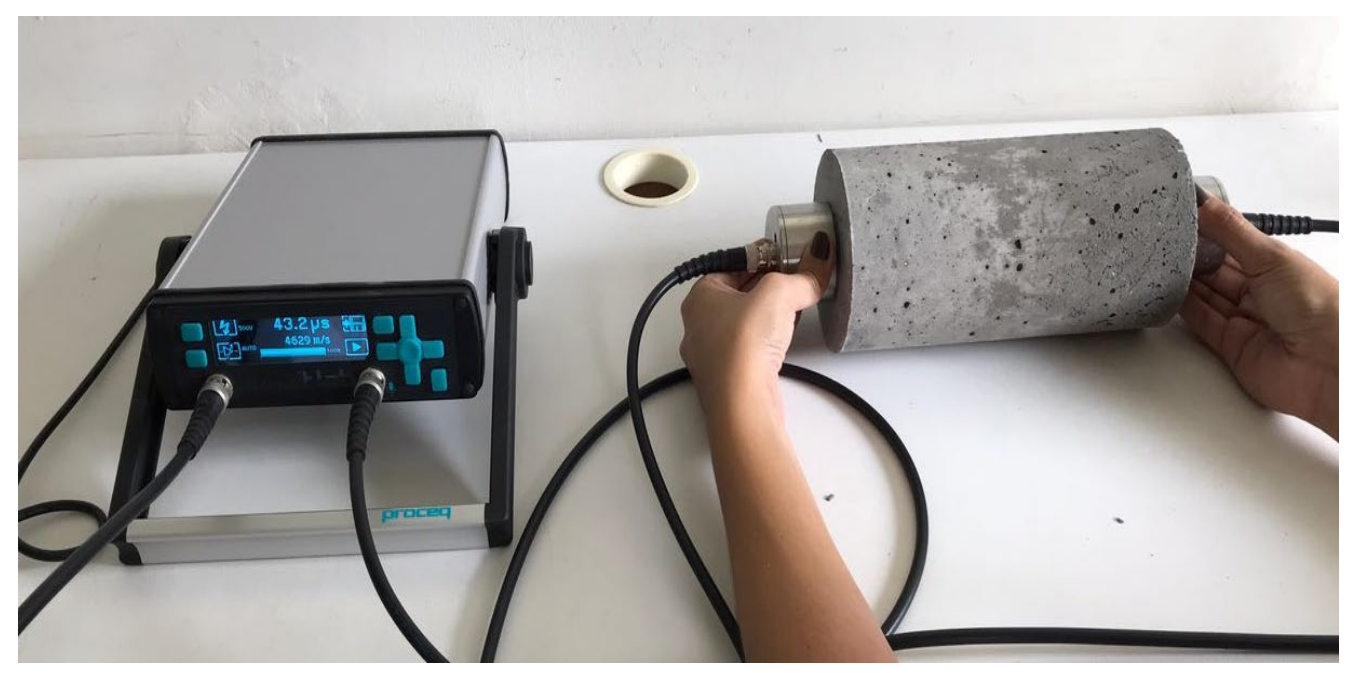

Figura 8. Execução do ensaio de ultrassom

Este ensaio determina a velocidade de propagação da onda ultrassônica no corpo de prova de concreto. A frequência da onda foi de $54 \mathrm{KHz}$. A velocidade de pulso, $\mathrm{V}$, de ondas longitudinais numa massa de concreto está relacionada com as suas propriedades elásticas e sua massa específica. O módulo de elasticidade dinâmico pode ser obtido a partir da expressão da ASTM C 597-16 (Equação 1), isolando-se essa variável nesta equação.

$$
V=\sqrt{\frac{E(1-\mu)}{\rho(1+\mu)(1-2 \mu)}}
$$

Onde: $\mathrm{E}=$ módulo de elasticidade dinâmico; $\mu=$ coeficiente de Poisson dinâmico; $\rho=$ massa específica do concreto.

\section{RESULTADOS}

\subsection{Concreto fresco}

As propriedades avaliadas no estado fresco dos concretos estão apresentadas na Tabela 4. Pode-se verificar que os concretos obtiveram valores de abatimento próximos, sendo o do C150 ligeiramente superior. Isso demonstra a possibilidade de reduzir o teor de cimento sem prejudicar a trabalhabilidade do concreto.

Tabela 4. Propriedades do concreto no estado fresco.

\begin{tabular}{|c|c|c|c|}
\hline Propriedade & C150 & C250 & C350 \\
\hline Massa Específica $\left(\mathrm{kg} / \mathrm{dm}^{3}\right)$ & 2,417 & 2,325 & 2,293 \\
\hline Abatimento $(\mathrm{cm})$ & 24,0 & 21,5 & 21,5 \\
\hline
\end{tabular}




\subsection{Resistência à compressão}

A Figura 9 ilustra os valores de resistência à compressão aos 28 dias dos concretos estudados. Observa-se que o concreto com consumo de cimento de $250 \mathrm{~kg} / \mathrm{m}^{3}$ obteve o maior valor de resistência, sendo $38 \%$ superior à alcançada pelo $\mathrm{C} 350$. Esse por sua vez, apresentou resistência superior ao $\mathrm{C} 150 \mathrm{em} 20 \%$.

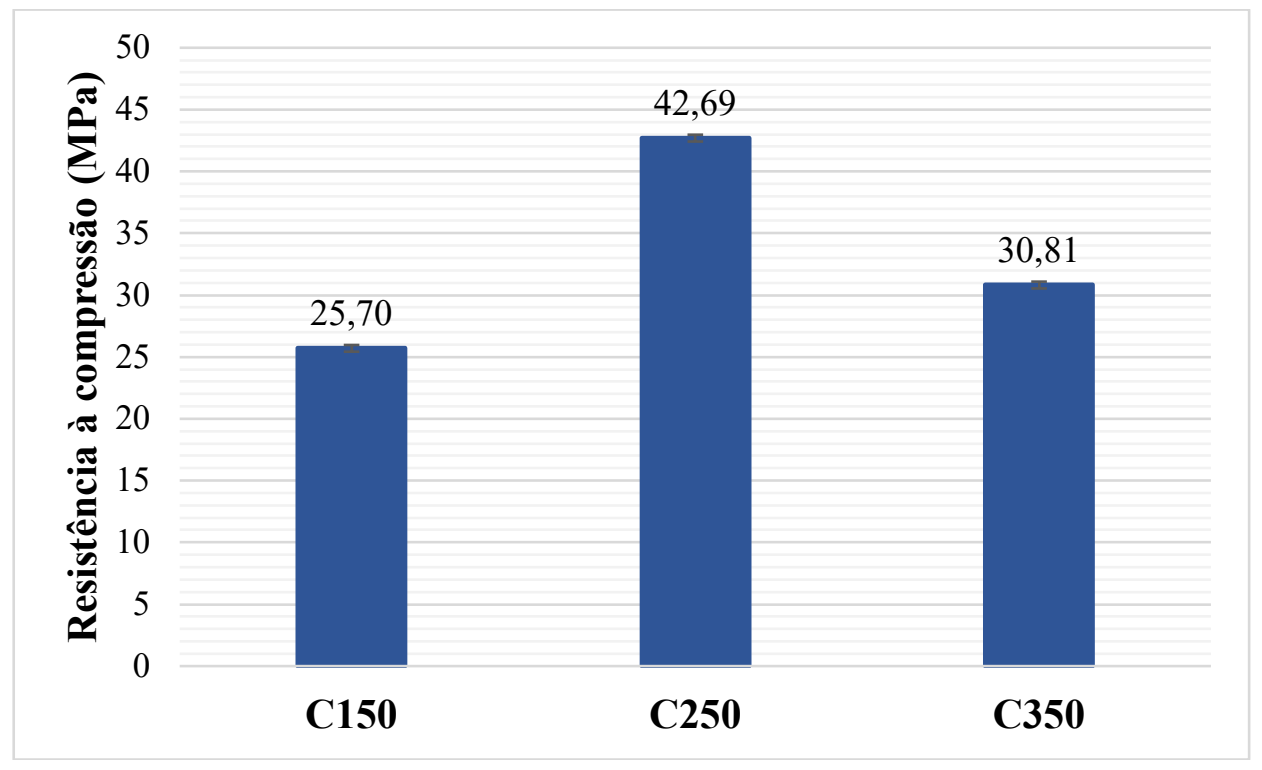

Figura 9. Resistência à compressão aos 28 dias

O indicador de Intensidade de Ligante (IL), proposto por Damineli (2010), relaciona o consumo total de ligante do concreto com a resistência à compressão. Este IL foi calculado para os concretos estudados e estão apresentados na Tabela 5. O consumo de ligante foi calculado considerando que O cimento é composto por aproximadamente $5 \%$ de $\mathrm{CaCO}_{3}$, sendo, portanto, $95 \%$ de ligante, conforme resultados apresentados no ensaio de Termogravimetria (TG).

Tabela 5. Indicador de desempenho Intensidade Ligante

\begin{tabular}{|l|c|c|c|}
\hline & C150 & C250 & C350 \\
\hline Resistência aos 28 dias (MPa) & 25,7 & 42,7 & 30,8 \\
\hline Consumo de ligante $\left(\mathrm{kg} / \mathrm{m}^{3}\right)$ & 143 & 238 & 333 \\
\hline IL $\left(\mathrm{kg} \cdot \mathrm{m}-{ }^{3} \cdot \mathrm{MPa}-1\right)$ & 5,6 & 5,6 & 10,8 \\
\hline
\end{tabular}

Os valores do IL dos concretos com baixo consumo de ligante ficaram semelhantes e próximo ao mínimo encontrado na literatura, que são ligeiramente inferiores a $5 \mathrm{~kg} \cdot \mathrm{m}^{-3} \cdot \mathrm{MPa}^{-1}$. Já o concreto de referência apresenta valor dentro do intervalo mais comum, conforme pode ser visualizado na Figura 10. É possível perceber que, pelos dados da literatura, os menores valores de IL são para concretos de maiores resistências. Porém, conforme o resultado que obtivemos, fica evidenciado que é possível obter concretos mais eficientes em classes de resistências mais baixas. 


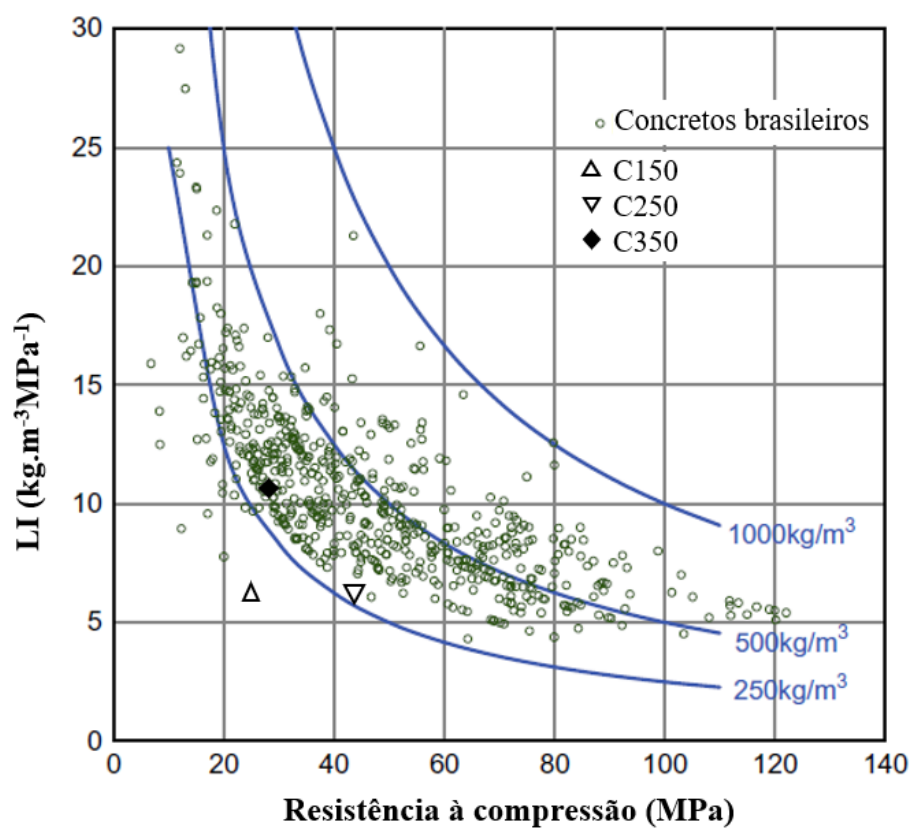

Figura 10. Intensidade Ligante versus Resistência à compressão aos 28 dias. Adaptado de Damineli et al., 2010.

\subsection{Absorção por imersão e por capilaridade}

Os valores de massa específica real e da amostra seca, na idade de 28 dias, estão apresentados na Tabela 6. Os concretos com menores teores de cimento apresentam índice de vazios e de absorção próximos, como pode ser visualizado na Figura 11. Já o concreto de referência apresentou $60 \%$ de aumento no teor de vazios em relação aos concretos com baixo teor de ligante. Isso demostra a contribuição das adições minerais no empacotamento da pasta, e consequentemente, no menor volume de vazios. O maior teor de vazios gerou também uma maior absorção de água no C350.

Do ponto de vista de durabilidade, sabe-se que quanto menor for a porosidade do concreto, mais difícil será a entrada de agentes agressivos que podem desencadear a corrosão das armaduras. Portanto, devido ao seu baixo volume de vazios dos concretos C150 e C250, espera-se que esses concretos tenham uma durabilidade satisfatória.

Tabela 6. Massa específica dos concretos aos 28 dias.

\begin{tabular}{|c|c|c|}
\hline Concreto & $\begin{array}{c}\text { Massa específica } \\
\text { da amostra seca } \\
\left(\mathbf{g} / \mathbf{c m}^{\mathbf{3}}\right)\end{array}$ & $\begin{array}{c}\text { Massa específica } \\
\text { real }\left(\mathbf{g} / \mathbf{c m}^{\mathbf{3}}\right)\end{array}$ \\
\hline $\mathbf{C 1 5 0}$ & 2,33 & 2,50 \\
\hline $\mathbf{C 2 5 0}$ & 2,27 & 2,43 \\
\hline $\mathbf{C 3 5 0}$ & 2,14 & 2,39 \\
\hline
\end{tabular}




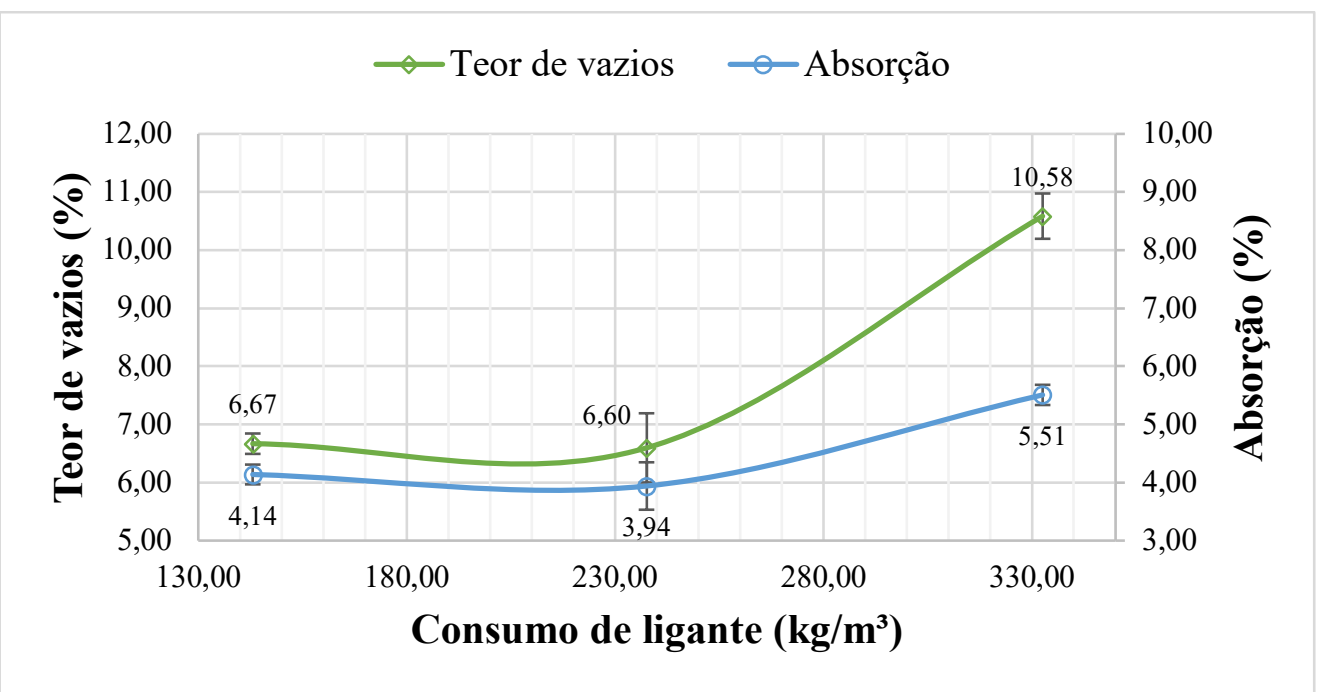

Figura 11. Teor de vazios e absorção dos concretos com diferente consumo de ligante.

Plotando-se um gráfico com os valores da absorção de água por capilaridade $\mathrm{C}\left(\mathrm{g} / \mathrm{cm}^{2}\right)$ em função da raiz quadrada do tempo, é possível verificar uma relação linear, ilustrando na Figura 12. A inclinação dessa curva pode ser tomada como o coeficiente de absorção capilar.

O coeficiente de absorção capilar do $\mathrm{C} 150$ e do $\mathrm{C} 250$ foi de $9,2 \times 10^{-3} \mathrm{~g} / \mathrm{cm}^{2} \mathrm{~s}^{0,5}$ e $7,5 \times 10^{-3} \mathrm{~g} / \mathrm{cm}^{2} \mathrm{~s}^{0,5}$, respectivamente. Já o de referência apresentou coeficiente mais elevado, no valor de $11,5 \times 10^{-3}$ $\mathrm{g} / \mathrm{cm}^{2} \mathrm{~s}^{0,5}$. O maior coeficiente de absorção capilar do $\mathrm{C} 150$ em relação ao $\mathrm{C} 250$ pode ser justificado pela sua estrutura porosa, que possivelmente apresenta poros de menores diâmetros, favorecendo uma absorção capilar mais rápida. Já o coeficiente de absorção do C350 aproximadamente 49\% superior ao $\mathrm{C} 250$, corroborando os resultados apresentados no ensaio de absorção por imersão que demonstrou que o seu teor de vazios que é muito mais elevado que os demais. Além disso, possivelmente sua estrutura porosa apresenta uma maior interconexão dos poros.

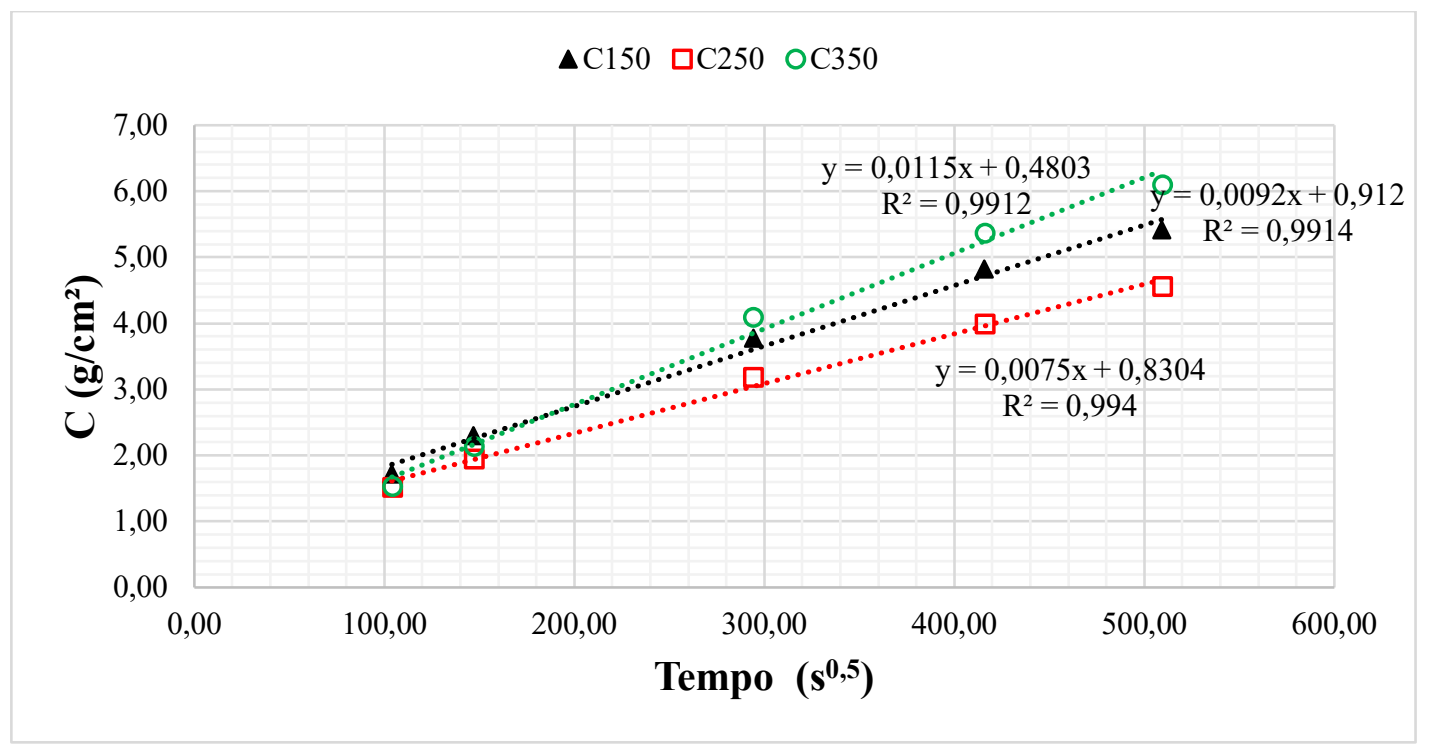

Figura 12. Absorção por capilaridade 


\subsection{Velocidade de propagação de onda ultrassônica}

Os valores da velocidade de propagação da onda ultrassônica através do concreto estão apresentados na Tabela 7, bem como a classificação da qualidade do concreto devido a esse parâmetro, segundo a norma BIS 13311-92. O valor da velocidade do pulso no C250 foi superior em 1,2\% em relação ao C150, e em 4,8\% em relação ao concreto de referência. Comparando os valores de velocidade de pulso obtidos neste estudo com os valores de velocidade de pulso dados na BIS: 13311-92, a qualidade dos concretos com baixo teor de cimento pode ser classificada como excelente, e o concreto de referência, com qualidade boa. Esses resultados indicam que a qualidade das misturas de concreto com filer calcário em termos de densidade, homogeneidade e uniformidade foi boa. Isso está de acordo com o resultado de absorção e teor de vazios, comprovando que a otimização granulométrica nos finos, juntamente com a redução do fator água/ligante e uma dispersão das partículas finas, interfere na estrutura porosa, com possíveis modificações na sua distribuição, diâmetro e interligações.

Tabela 7. Classificação da qualidade do concreto de acordo com a velocidade do pulso

\begin{tabular}{|c|c|c|c|}
\hline \multirow{2}{*}{ Concreto } & $\begin{array}{c}\text { Velocidade } \\
\text { do pulso } \\
\text { ultrassônico } \\
(\mathbf{m} / \mathbf{s})\end{array}$ & $\begin{array}{c}|c| \\
\text { Classificação da qualidade do concreto de acordo } \\
\text { com a norma BIS 13311-92 }\end{array}$ \\
\cline { 2 - 4 } & $\mathbf{2 8 d}$ & Velocidade do pulso (m/s) & $\begin{array}{c}\text { Qualidade do } \\
\text { concreto }\end{array}$ \\
\cline { 2 - 4 } & 4591,54 & $>4500$ & Excelente \\
\hline $\mathrm{C} 150$ & 4646,83 & $3500-4500$ & Boa \\
\hline $\mathrm{C} 250$ & 4435,47 & $3000-3500$ & Média \\
\hline $\mathrm{C} 350$ & & $<3000$ & Duvidosa \\
\hline
\end{tabular}

O módulo de elasticidade dinâmico foi obtido, indiretamente, por meio do ensaio de Ultrassom e está ilustrado na Figura 13. Apesar do C350 apresentar resistência à compressão superior ao C150, o seu valor de módulo de elasticidade foi inferior. Isso se deve à maior densidade do C150 alcançada devido à otimização de sua pasta.

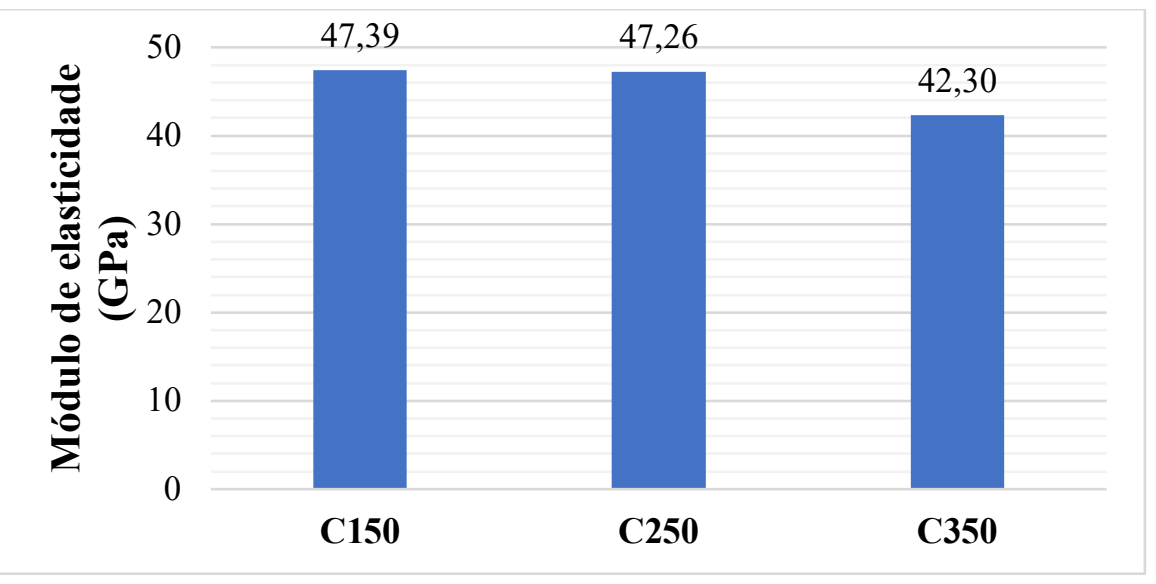

Figura 13. Módulo de elasticidade aos 28 dias. 


\section{CONCLUSÕES}

Dos resultados apresentados nesse estudo, pode-se concluir:

1. O concreto com consumo de cimento de $250 \mathrm{~kg} / \mathrm{m}^{3}$ apresentou a resistência à compressão superior ao concreto de referência, com consumo de cimento de $350 \mathrm{k} / \mathrm{m}^{3}$. Já o concreto com teor de cimento de $150 \mathrm{~kg} / \mathrm{m}^{3}$, apesar do menor valor de resistência mecânica, sendo $17 \%$ inferior ao de referência, obteve a melhor eficiência medida pelo indicador IL. Portanto, foi verificado que é possível produzir concretos de classe de resistência mais baixa com IL próximos aos mais eficientes encontrados na literatura.

2. Os concretos eco eficientes, C150 e C250, apresentaram características de menor absorção de água e menor teor de vazios do que o concreto de referência. É possível, portanto, que os concretos otimizados apresentem maior durabilidade do que o C350.

3. Apesar da maior resistência à compressão do $\mathrm{C} 250$ em relação ao $\mathrm{C} 150$, os valores próximos de teor de vazios demonstram que é possível elaborar concretos com diferente resistência mecânica, mas semelhante porosidade, mesmo com consumo de material ligante distintos.

4. Os menores valores de coeficiente de absorção capilar em relação ao C350 indicam que a otimização da pasta, utilizando o filer calcário, interfere da estrutura porosa do concreto, favorecendo para redução de volume de poros e possivelmente, menores interconexões.

5. A velocidade de propagação de ondas ultrassônicas nos concretos demonstrou a contribuição do empacotamento dos finos na qualidade do concreto. Os concretos C150 e C250 foram classificados como concretos de qualidade excelente, enquanto o concreto de referência foi classificado como qualidade boa.

6. A redução do consumo de cimento Portland no concreto é possível, desde que seja realizada uma otimização da pasta, com uso de filer calcário, dispersantes e adequada relação água/ligante. O concreto com menor teor de cimento pode apresentar melhor desempenho mecânico e de durabilidade, além de ter vantagens ambientais importantes no atual contexto de sustentabilidade.

\section{AGRADECIMENTOS}

Essa pesquisa é parte do projeto CEMtec- National Institute on Advanced Eco-Efficient Cement Based Technologies, apoiado pelo Conselho Nacional de Desenvolvimento Científico e Tecnológico - CNPq (Processo 485340/2013-5) e pela Fundação de Apoio à Pesquisa de São Paulo (FAPESP) (Processo 14/50948-3 INCT/2014). Agradecemos ao Laboratório de Microestrutura e Ecoeficiência (LME) da USP, ao Grupo de Pesquisa de Materiais de Construção e Resíduo (GMAT) do IFPB e ao Laboratório de Ensaios de Materiais e Estruturas (LABEME) pelo apoio técnico oferecido. 


\section{REFERÊNCIAS}

Associação Brasileira De Normas Técnicas (1998). NBR NM 67: Concreto- Determinação da consistência pelo abatimento do tronco de cone. Rio de Janeiro.

Associação Brasileira De Normas Técnicas (2008). NBR 9833: Concreto fresco - Determinação da massa específica, do rendimento e do teor de ar pelo método gravimétrico. Rio de Janeiro.

Associação Brasileira De Normas Técnicas (2007). NBR 5739: Concreto - Ensaios de compressão de corpos-de-prova cilíndricos. Rio de Janeiro.

Bureal of Indian Standards (1991). BIS-11331: Indian Standard Specification for Non-destructive Testingof Concrete: Part-1 Ultrasonic Pulse Velocity. NewDelhi, India.

ASTM International (2002). ASTM C597-02. Standard Test Method for Pulse Velocity Through Concrete.

ASTM International (2013). ASTM C646-13. Standard Test Method for Density, Absorption, and Voids in Hardened Concrete.

ASTM International (2013). ASTM C1585-13. Standard Test Method for Measurement of Rate of Absorption of Water by Hydraulic-Cement Concretes.

Conselho Brasileiro De Construção Sustentável (2014). "Aspectos da Construção Sustentável no Brasil e Promoção de Políticas Públicas: Subsídios para a promoção da Construção Civil Sustentável"

Damineli, B. L.; Kemeid, F. M.; Aguiar, P. S.; John, V. M. (2010), Measuring the eco-efficiency of cement use. Cement and Concrete Composites, v. 32, n. 8, p. 555-562.

Intergovernmental Panel On Climate Change - IPCC (2021), Summary for Policymakers. In: Climate Change 2021: The Physical Science Basis. Contribution of Working Group I to the Sixth Assessment Report of the Intergovernmental Panel on Climate Change. Cambridge University Press.

Müller, H. S.; Breiner, R.; Moffatt, J. S.; Haist, M (2014), Design and Properties of Sustainable Concrete. Procedia Engineering, v. 95, p. 290-304.

Proske, T.; Hainer, S.; Rezvani, M.; Graubner, C (2014). A. Eco-friendly concretes with reduced water and cement content - Mix design principles and application in practice. Construction and Building Materials, v. 67, p. 413-421.

Rebmann, M. S. (2011), "Durabilidade de concretos estruturais com baixo consumo de cimento Portland e alta resistência." Dissertação de mestrado. Escola de Engenharia de São Carlos da Universidade de São Paulo, São Carlos.

Rebmann, M. S.; Liborio, J. B. L. (2013), Durabilidade de concretos estruturais com baixo consumo de cimento. Concreto \& Construções, n. 71.

Smol, M.; Kulczycka, J.; Henclik, A.; Gorazda, K.; Wzorek, Z.(2015) The possible use of sewage sludge ash (SSA) in the construction industry as a way towards a circular economy. Journal of Cleaner Production, v. 95, p. 45-54. 